\title{
Análise ambiental integrada da localidade de sambaqui na microbacia hidrográfica do Rio Sagrado, Morretes (PR) ${ }^{1}$
}

\section{Resumo}

A presente Pesquisa está em curso no contexto da Zona de Educação para o Ecodesenvolvimento (ZEE), localizado na APA de Guaratuba, caracterizada por vasta produção de plantas ornamentais e hortifrutigranjeiros. Valendose da importância do planejamento baseado no compartilhamento de sabedorias tradicionais incorporadas ao conhecimento científico, o presente estudo procurou identificar e caracterizar as unidades da paisagem através da elaboração de transectos geoambientais. Os resultados da pesquisa identificaram que a localidade de Sambaqui, situada em área morfologicamente plana e regular, é adequada ao uso e ocupação do solo. Caracterizada como uma das áreas deposicionais de materiais decorrentes das corridas de massa e detrito, Sambaqui sofre com enchentes que alteram a largura e o curso do rio. Com a postura de que é preciso prevenir muito mais do que corrigir, o processo de planejamento implementado segue com diagnóstico e prognóstico que identifica vocações e limitações para o uso do solo e dos recursos naturais.

Palavras-chave: Desenvolvimento econômico - aspectos ambientais; Desenvolvimento sustentável; Impacto ambiental; Microbacia hidrográfica do Rio Sagrado - Morretes (PR).

\author{
Alice Garbari \\ Graduanda em Arquitetura e \\ Urbanismo na Fundação \\ Universidade Regional de \\ Blumenau - FURB - Brasil \\ alicegarbari.arq@gmail.com

\section{Cristiane Mansur de Moraes} \\ Souza \\ Doutora em Ciências Humanas \\ pela Universidade Federal de \\ Santa Catarina - UFSC; \\ Professora na FURB - Brasil \\ arqcmansur@gmail.com
}

\section{Juarês José Aumond}

Doutor em Engenharia Civil pela UFSC; Professor na FURB - Brasil juares.aumond@gmail.com

Samara Braun

Mestranda na FURB - Brasil samii.braun@gmail.com

\section{Juliana Pilan}

Graduada em Arquitetura e Urbanismo pela FURB - Brasil ju.pilan@hotmail.com

\footnotetext{
${ }_{1}^{1}$ Projeto de pesquisa Análise Ambiental Integrada dos Fatores Físico-Naturais e Antrópicos da Localidade de Sambaqui, Microbacia Hidrográfica do Rio Sagrado, Morretes, (PR), Zona de Educação para o Ecodesenvolvimento; com apoio do CNPq.
} 


\title{
Integrated environmental analysis of locantion of sambaqui in the hydrographic basin of Rio Sagrado, Morretes (PR)
}

\begin{abstract}
This study is about the identification and characterization of the landscape through the evaluation of geo-environmental drawing and field studies called transects. It also considers traditional wisdom joined with scientific knowledge by incorporating local people opnions. The study is about Sambaqui, State of Parana, (Brazil), where it can be found an extensive production of ornamental plants and horticultural. The study results have identified that the area of Sambaqui, is appropriated for urbanization, and also located in morphologically flat area. Sambaqui is often affected by floods that have changed the design of the river. It is recommended that planning process should implement a diagnosis and a prognosis, as such, that identifies vocations and limitations for land use and natural resources.
\end{abstract}

Keywords: Economic development - environmental aspects ; Sustainable development; Environmental impact; Rio Sagrado basin - Morretes, Paraná (Brazil).

\section{Para citar este artigo:}

GARBARI, Alice; SOUZA, Cristiane Mansur de Moraes; AUMOND, Juarês José; BRAUN, Samara; PILAN, Juliana. Análise ambiental integrada da localidade de sambaqui na microbacia hidrográfica do Rio Sagrado, Morretes (PR). Revista PerCursos. Florianópolis, v. 16, n.30, p. 143 -161. jan./abr. 2015.

\section{DOI: $10.5965 / 1984724616302015143$}

http://dx.doi.org/10.5965/1984724616302015143 


\section{Introdução}

O processo de mudanças climáticas e ambientais globais que vêm se agravando

processo de mudanças climáticas e ambientais globais que vêm se agravando nas últimas décadas foi divulgado mais abertamente através das mídias há poucos anos, trazendo à tona grandes preocupações e questionamentos quanto à direção para onde a humanidade caminha. Grandes desastres naturais são alastrados pelo mundo, alguns decorrentes de longos processos, outros inesperados, arrasando vilas ou cidades. No entanto, fato é que os riscos associados às mudanças climáticas globais não podem ser avaliados isoladamente ao contexto referente à globalização, e sim às mudanças ambientais e à precarização de sistemas de governo (MALUF, ROSA, 2011).

O aumento significativo do desmatamento e alteração dos ecossistemas naturais, assim como os impactos dos processos socioeconômicos e culturais, o aumento do consumo de recursos naturais e da demanda sobre os ciclos biogeoquímicos, se deve pelo crescimento da ocupação humana e pelas mudanças climáticas, refletindo na necessidade de manejo sustentável na retirada de recursos naturais (BARCELOS, BARRIEL, 2009). Tais problemas ambientais necessitam de uma abordagem diferenciada, com novos padrões de organização e abandono de práticas tradicionais, afinal problemas atuais surgem de tratamentos interdependentes a determinada parte de um meio ambiente (BERTALANFFY, 1968).

As mudanças climáticas refletem o impacto de processos socioeconômicos e culturais, como o crescimento populacional, a urbanização, a industrialização e o aumento do consumo de recursos naturais e da demanda sobre os ciclos biogeoquímicos (BARCELOS, BARRIEL, 2009). As medidas de mitigação referem-se ao âmbito regional e local, o qual deve ser tratado de maneira pragmática, inclusive com o desenvolvimento de cenários alternativos, como sugerem as Zonas de Educação para o Ecodesenvolvimento ZEE, em particular a ZEE do Rio Sagrado, presente área de estudo. Trabalhos de campanha após os eventos climáticos como o de 11 de março de 2011, ocorridos no litoral do Paraná, mostram deslizamentos e cheias sem precedentes, provocados pelas chuvas intensas e resultado do modelo de uso e ocupação do solo vigente. 
Evidencia-se, então, a necessidade de uma análise dos fatores físico-naturais que venha a subsidiar a formação de agricultores locais. O foco principal aqui abordado integra uma pesquisa aplicada avaliativa. O marco metodológico alia a cartografia temática ambiental ao sistema de informações geográficas, visando à construção da análise das condições ambientais locais.

\section{Área de estudo e suas características}

O manejo integrado em microbacias hidrográficas está sendo amplamente difundido, em nível internacional, como uma importante opção estratégica para o desenvolvimento regional. Em seu conceito técnico, a microbacia é definida como uma área geográfica de captação de água composta por pequenos canais de confluência e delimitada por divisores naturais (FIGUEREDO, 1999).

A Microbacia de Rio Sagrado localiza-se integralmente na área rural do município litorâneo de Morretes, no Paraná, que fica a sudeste do estado paranaense e situa-se a 68 km da capital, Curitiba, na vertente oriental da Serra do Mar. Possui $137,7 \mathrm{~km}^{2}$ e se encontra entre a Serra do Mar e a Planície Litorânea do estado (NOWATZK, VEDOR DE PAULA, SANTOS, 2009). O clima é classificado como submontano (temperado quente) úmido e muito úmido, com temperatura anual de $15^{\circ} \mathrm{C}$ a $19^{\circ} \mathrm{C}$ e mínima absoluta de $-5^{\circ} \mathrm{C}$ a $10^{\circ} \mathrm{C}$. (CARPANEZZI, 1986). A localização da microbacia na Serra do Mar é caracterizada por grande variação altimétrica de om a 1350m, condições propícias à formação de chuvas orográficas, contribuindo para umidade e chuvas elevadas no decorrer do ano. A precipitação média anual é de 1.250 a 2.500 mm (CARPANEZZI, 1986).

Segundo Keller Alves (2008), no local, concentra-se uma povoação de 520 famílias, das quais aproximadamente 270 são consideradas residentes - predominantemente pequenos proprietários rurais -, e 250 famílias não residentes, isto é, proprietários de chácaras ou sítios para o lazer. Trata-se de uma comunidade que busca mecanismos de adaptação na tentativa de superação de crises econômicas, baseando-se principalmente em atividades econômicas apoiadas na agricultura familiar e no artesanato com fibras naturais (bananeira e cipó imbé). 


\section{Fundamentação teórica}

Descrever o comportamento e as formas terrestres naturais e correlacioná-las aos fatores externos exige o uso da cartografia, da análise e da pesquisa empírica. "Pode-se imaginar que o globo terrestre é uma imensa peça de escultura, sobre a qual os processos naturais internos e externos agem, sendo responsáveis pela esculturação. O escultor é a própria natureza" (ROSS, 1990). No entanto, com o aumento significativo do desmatamento e alteração dos ecossistemas naturais, acentuam-se os impactos dos processos socioeconômicos e culturais. A presente demanda sobre os ciclos biogeoquímicos se deve pelo crescimento da ocupação humana e pelas mudanças climáticas que vêm alterando rapidamente a dinâmica ambiental. A ação humana gera modificações no ambiente natural, alterando seu equilíbrio que apesar de não ser estático, parte de um dinamismo harmonioso. Essas modificações geram efeitos de agressão com graus correspondentes ao impacto causado, sendo estes de diferentes níveis, levando às vezes as condições ambientais a processos irreversíveis (ROSS, 1990).

Tais problemas ambientais necessitam uma abordagem diferenciada, com novos padrões de organização das comunidades científicas e abandono de práticas tradicionais disciplinares. Quando se tenta abordar problemas socioambientais, deve-se destacar o fato de que conhecimento revela tanto conjunto de certezas que se têm sobre a natureza, quanto fatores de incerteza, que não dependem apenas de causas naturais, mas também da intervenção ativa do homem sobre o mundo e das interações deste para com a natureza (HENRIQUÉZ et al., 2008).

Os impactos ambientais dependem da localização e da capacidade de carga dos ecossistemas relacionadas ao clima, topografia, densidade de ocupação humana e econômica e padrões de uso da terra. Neste sentido, é preciso considerar todos os problemas de forma unificada a partir da interdisciplinaridade, planejando assim o ecodesenvolvimento que, definido por Sachs (1986), é como um estilo de desenvolvimento que, em cada ecorregião, se investem soluções específicas de seus problemas particulares, levando em conta os dados ecológicos e culturais e estratégias de curto e longo prazo. O ecodesenvolvimento tenta reagir à moda preocupante das 
soluções universalistas e generalizadas; estando voltado para a ciência e para o futuro com ênfase na procura por potenciais de determinado ecossistema, em que o objetivo que se tem em mira é o de encontrar usos novos e imaginativos para os recursos atuando sobre quatro grupos de variáveis relativos à energia, uso de espaço, recursos e tecnologia (SACHS, 1986).

O variável uso do espaço pode dar continuidade a uma citação da vulnerabilidade ambiental, estudada a partir da identificação de áreas apropriadas e não apropriadas a ocupação humana, foco de estudo deste trabalho:

(...) as diversas alternativas de uso e ocupação das terras sobre diferentes terrenos sejam observados em macroescala ou em microescala, podem induzir, direta ou indiretamente, desastres ou situações indesejáveis ao Homem. Elas costumam alterar a dinâmica da paisagem, modificando a capacidade do meio em responder aos processos naturais. Se não podemos evitar determinadas forças e fenômenos da Natureza, por outro lado, podemos modificar, para melhor, as formas como as intervenções humanas atuam na paisagem. (SANTOS, 2007, Prefácio)

Assim, pesquisar um ecossistema que interage com a realidade, significa estudar um elemento que envolve aspectos físicos, biológicos, sociais, econômicos e políticos (SACHS, 1986). Garcia (1994) ainda defende que existem múltiplos aspectos e maneiras de abordar os ecossistemas, dependendo sempre dos objetivos perseguidos em cada processo de pesquisa. É preciso considerar os problemas de recursos, ambiente, população e desenvolvimento de forma unificada a partir da interdisciplinaridade, alcançando assim o ecodesenvolvimento proposto por Sachs (1986).

Eis uma temática com que ocupar toda uma geração de pesquisadores em ciências sociais. Na realidade, haverá que se estabelecer nova articulação entre as ciências do homem e as ciências naturais a fim de melhor apreender a interação dos processos naturais e sociais, nos quais o homem é igualmente sujeito e objeto. Acrescente-se: um sujeito consciente de sua dependência em relação à natureza de seu futuro. (SACHS, 1986). 
É neste contexto que se inscreve este projeto na Zona de Educação para o Ecodesenvolvimento (ZEE) do Rio Sagrado. Entendendo que educação para o ecodesenvolvimento conflui para "contribuir para a conservação da biodiversidade, para a auto-realização individual e comunitária, através de processos educativos/participativos que promovam a melhoria do meio ambiente e da qualidade de vida" (SORRENTINO, 1998, p.30).

A perspectiva teórica adotada neste estudo abre um campo de reflexão sobre a complexidade nas questões socioambientais, em que o desafio para analisar a vulnerabilidade ambiental se dá em alternativas para reduzir e mitigar os efeitos da alteração da paisagem (SANTOS, 2007), com a postura de que é preciso prevenir muito mais do que corrigir, de maneira as análises devem direcionar o uso dos recursos naturais, minimizando assim as sequelas causadas pelo homem na reordenação do espaço físico, tendo a ação preventiva sobre o ambiente como uma resultante bem mais barata do que medidas reparadoras (SACHS, 1986).

\section{Materiais e métodos}

Segundo Ross (1990, p. 32), "a metodologia deve representar a "espinha dorsal” de qualquer pesquisa". O domínio do conteúdo teórico e conceitual implica na habilidade de apoiar-se em bases a serem seguidas e adaptadas de acordo com as necessidades encontradas, apresentando domínio sobre o conhecimento específico e a técnica aplicada assim como as técnicas de apoio para execução do trabalho. São produtos cartográficos que ao mesmo tempo norteiam as pesquisas e tornaram-se representações sínteses do objeto pesquisado, em que o mapa é ao mesmo tempo instrumento de análise e documento de síntese da pesquisa (Figura 3).

A incorporação de revisões bibliográficas e a obtenção de informações primárias através de caminhadas geoambientais foram de enorme valia no desenvolvimento da pesquisa, em que o diagnóstico ambiental apresentado foi alcançado através de estratégias práticas e teóricas, nas quais a interação com a comunidade da Microbacia do Rio Sagrado possibilitou trocas produtivas de dados e informações, permitindo também à 
equipe uma análise consistente da realidade dos mesmos e sua relação com o meio ambiente. A colocação de Toledo e Barrera-Bassols (2009) remete à importância da existência das duas tradições intelectuais - o saber científico e o saber local -, cada uma com origens, traços e capacidades diferentes:

A nós, os pesquisadores treinados nos recintos acadêmicos da ciência moderna, ensinaram a entender as técnicas, a inventariar as espécies utilizadas, e a descobrir os sistemas de produção, energia e abastecimento por meio dos quais os grupos humanos se apropriam da natureza. Poucas vezes nos ensinaram a reconhecer a existência de uma experiência, de certa sabedoria, nas mentes de milhões de homens e mulheres que dia após dia trabalham a natureza precisamente mediante essas técnicas, essas espécies e esses sistemas. Hoje, no alvorecer de um novo século, esses homens e mulheres formam ainda a maior parte da população dedicada a apropriar-se dos ecossistemas do planeta. E é justamente esse esquecimento da investigação científica o que fez com que a civilização industrial fracassasse em suas tentativas de realizar um manejo adequado da natureza. (TOLEDO; BARRERA-BALSSOLS, 2009, p. 32)

As sabedorias tradicionais se fundamentam nas experiências que se têm sobre o mundo, seus feitos e significados, e sua valorização de acordo com o contexto natural e cultural em que se estendem, sendo assim a participação de membros da comunidade na coleta de informações serviram para o reconhecimento real da Microbacia.

Os transectos, aqui denominados caminhadas geoambientais, baseiam-se na coleta de informações durante caminhadas de reconhecimento de uma dada área, mediante observações sistemáticas da morfologia e geologia dos recursos e atividades humanas ali existentes (Seixas, 2005). Essas caminhadas permitem que os pesquisadores se familiarizem com a área em estudo. Sobre a representação do transecto são colocadas as informações sociais e ambientais obtidas, bem como os principais problemas e possíveis soluções levantadas. Além dessas informações foram registradas imagens e dados sobre a forma da paisagem geográfica para a elaboração dos perfis geológicos aqui apresentados. 
As caminhadas geoambientais compõem uma relação entre sabedoria tradicional e conhecimento científico desenvolvido por uma equipe interdisciplinar englobando graduandos de Arquitetura e Urbanismo e Ciências Biológicas, assim como professores com formação em Geologia, Geografia e Arquitetura e Urbanismo, contando ainda com apoio de mestrandos na área de Desenvolvimento Regional. A interdisciplinaridade incentiva a integração operativa e cooperativa na busca por resoluções complexas referentes ao desenvolvimento, produzindo uma metodologia híbrida (LEFF, 1994).

O método procurou aproveitar da melhor maneira possível as saídas de campo, trabalhando junto com membros da comunidade, que puderam fornecer informações como a localização de áreas suscetíveis a enxurradas, deslizamento, desmatamento entre outros. O levantamento de dados obtidos nas caminhadas geoambientais foi interpretado e cruzado com as cartas temáticas obtidas e/ou elaboradas pela equipe, possibilitando o desenvolvimento de informações geomorfológicas e geológicas que venham a completar o estudo.

A definição de indicadores ou variáveis a serem utilizados na pesquisa foi determinada a partir da visão sistêmica, partindo-se da convicção de que não é possível considerar fenômenos ambientais e climáticos do meio físico-natural sem analisar as relações entre eles, como sugere a teoria sistêmica de Von Bertalanffy (1968). Nela se considera que os fenômenos naturais, em sua maioria, se constituem em sistemas dinâmicos complexos que apresentam uma dinâmica evolutiva determinada pela sua estrutura e pelos fatores externos (AUMOND, 2009). Para enfrentar esta problemática, esta pesquisa envolve profissionais da Geografia, Geologia, Arquitetura e Engenharia Florestal que, integrados, deverão convergir para o âmbito de uma problemática compartilhada.

\section{Resultados}

Sambaqui é a área mais densamente ocupada pelas atividades humanas, sendo a que apresenta maiores e mais graves impactos ambientais decorrentes da ação antrópica. 
Organiza-se aos arredores do Rio Sambaqui ou Lageado, fazendo divisa com Zoador a Sul, e com Pitinga a Oeste e Sudoeste.

Por se constituir a área morfologicamente mais plana e regular, a localidade de Sambaqui é adequada ao uso e ocupação do solo devido a sua declividade e também à fertilidade oferecida pelos solos muito propícios para agricultura intensiva e extensiva, como já têm se mostrado historicamente. Esta área é caracterizada pela vasta produção de plantas ornamentais; hortifrutigranjeiros, como frutas cítricas, palmito e banana; e hortaliças em geral, como por exemplo, tomate, chuchu, pepino, feijão de vara. Tendo em sua paisagem a presença de pastagens e banhado. Muitas pastagens e cultivos encontram-se abandonados, conforme moradores, devido ao custo elevado da mão de obra ou pela falta de interesse dos herdeiros.

A localidade de Sambaqui, situada na região nordeste da Microbacia de Rio Sagrado, por encontrar-se nas porções mais baixas e planas é caracterizada como uma das áreas deposicionais dos materiais decorrentes das corridas de massa e detrito das porções mais altas. Devido a torrentes ocasionadas nas comunidades acima (Zoador e Morro Alto) (figura 1), Sambaqui sofre com enchentes, alterando a largura do curso do rio. Nesta área, ocorrem apenas os processos deposicionais, constituídos por sedimentos fluviais inconsolidados.

Através de análises e interpretações de cartas temáticas (figura 2, 3) e caminhadas geoambientais, a área ocupada pela localidade de Sambaqui, em especial, pode ser classificada em duas unidades de paisagem (figura 1), diferente das demais localidades da microbacia que chegaram a apresentar quatro tipologias de paisagens devidas, principalmente, as suas maiores variedades altimétricas. Tal divisão possibilitou a identificação das áreas apropriadas para ocupação humana e prática de agricultura, compatíveis com a geografia apresentada. 


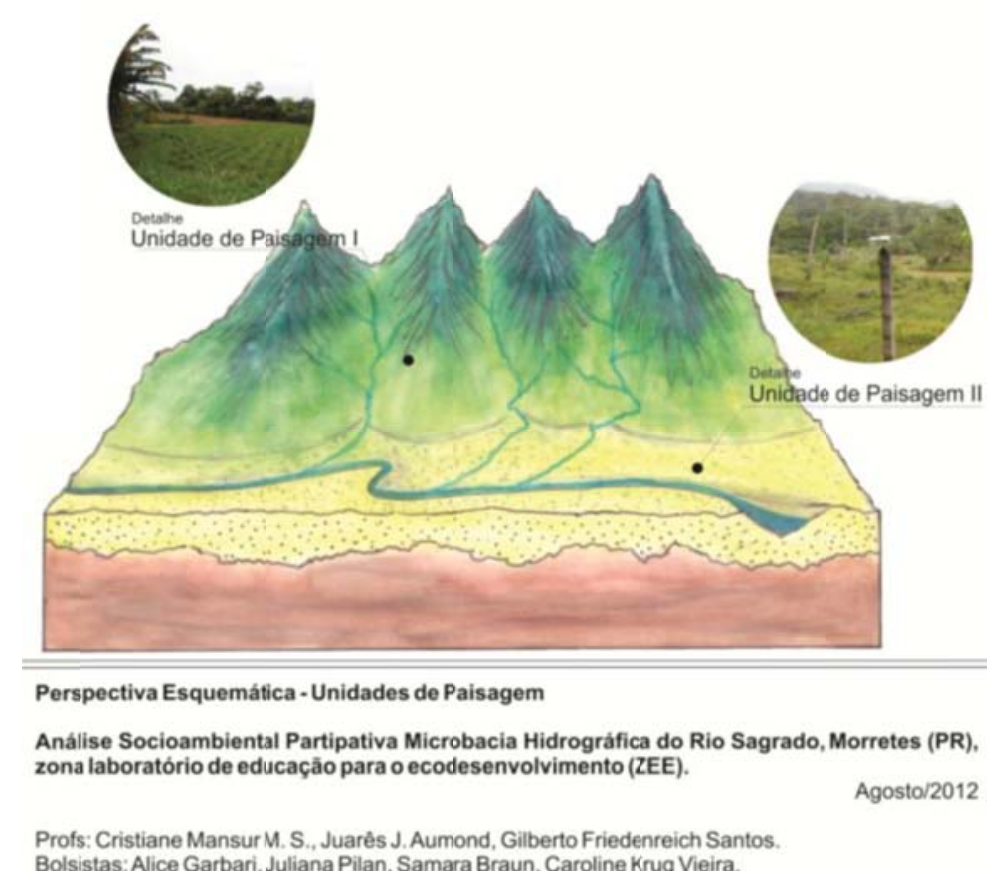

Bolsistas: Alice Garbari, Juliana Pilan, Samara Braun, Caroline Krug Vieira.

Figura 1 - Perspectiva Esquemática da Localidade de Sambaqui Fonte: Resultado da Pesquisa - arquivo dos autores.

\section{Primeira unidade de paisagem}

A primeira unidade de paisagem é caracteriza-se por ser a área altimétrica mais elevada da localidade, possuindo altitude de 160 metros a 320 metros e declividade entre $10,01^{\circ}$ e $45^{\circ}$. Por se tratar de uma localidade basicamente plana, esta unidade é encontrada em menor escala, sendo mais intensa em seus limites territoriais, principalmente na divisa com a localidade de Pitinga. Geologicamente é composta principalmente por argissolos havendo predominância do Complexo GnáissicoMigmatítico (Figura 4). 


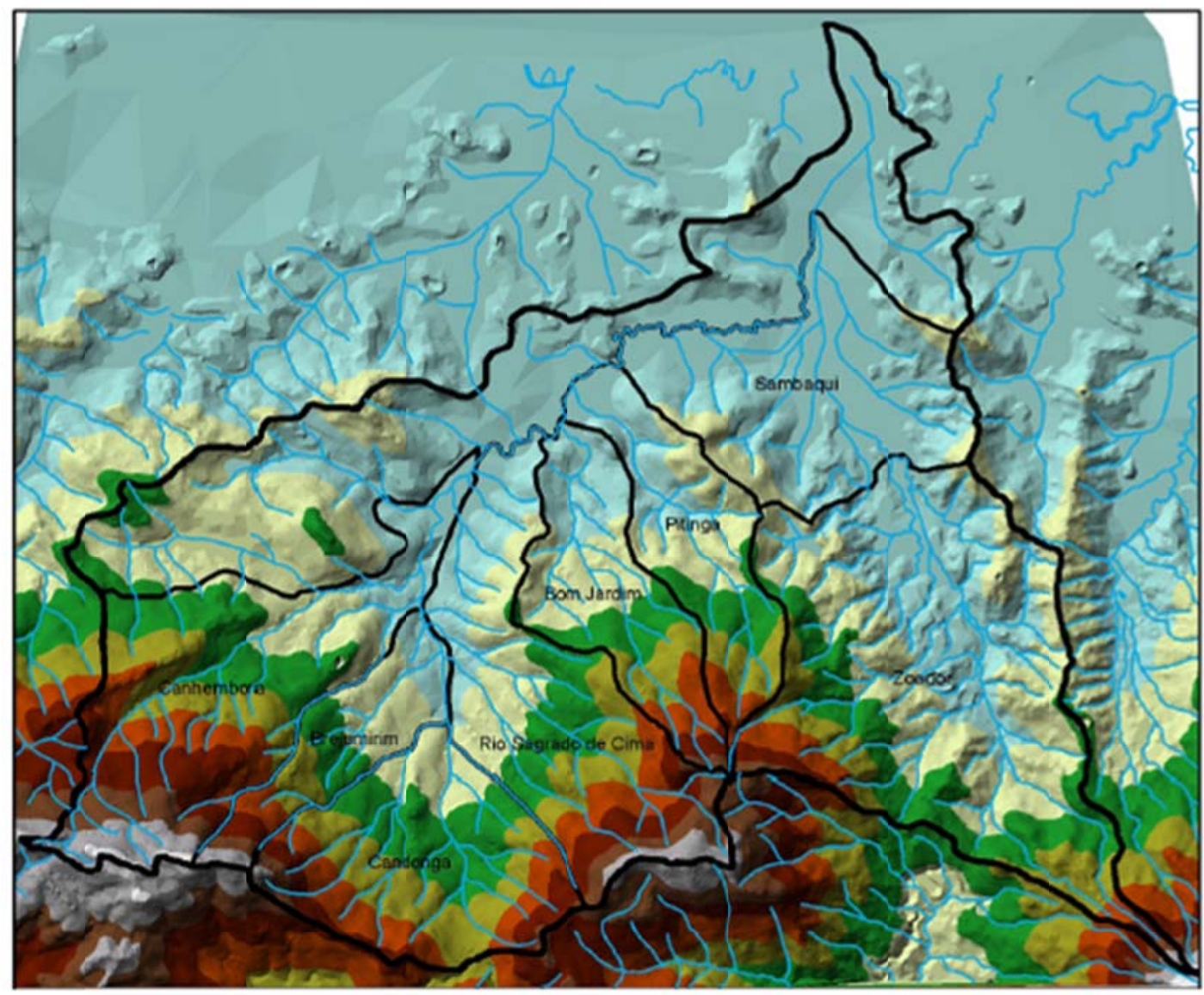

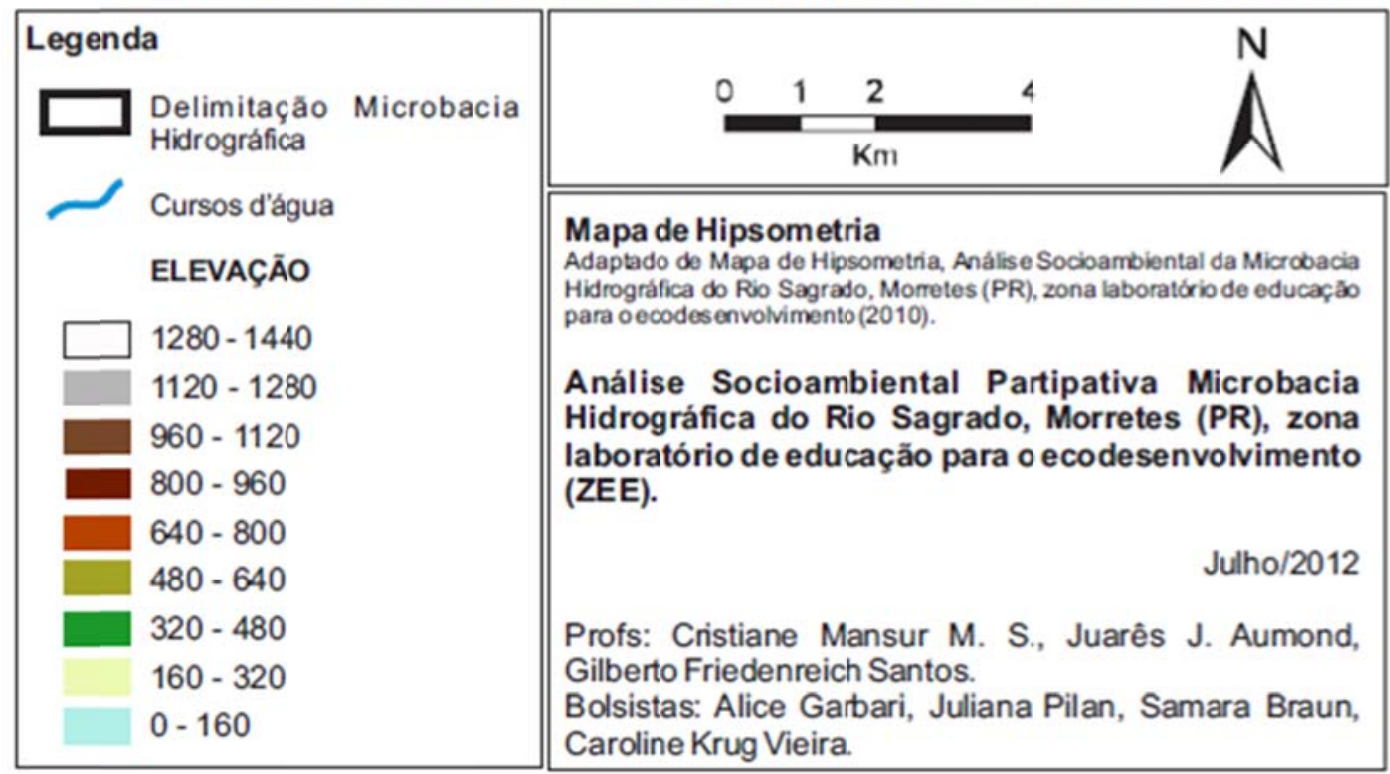

Figura 2 - Mapa de Hipsometria

Fonte: Resultado da Pesquisa - arquivo dos autores. 

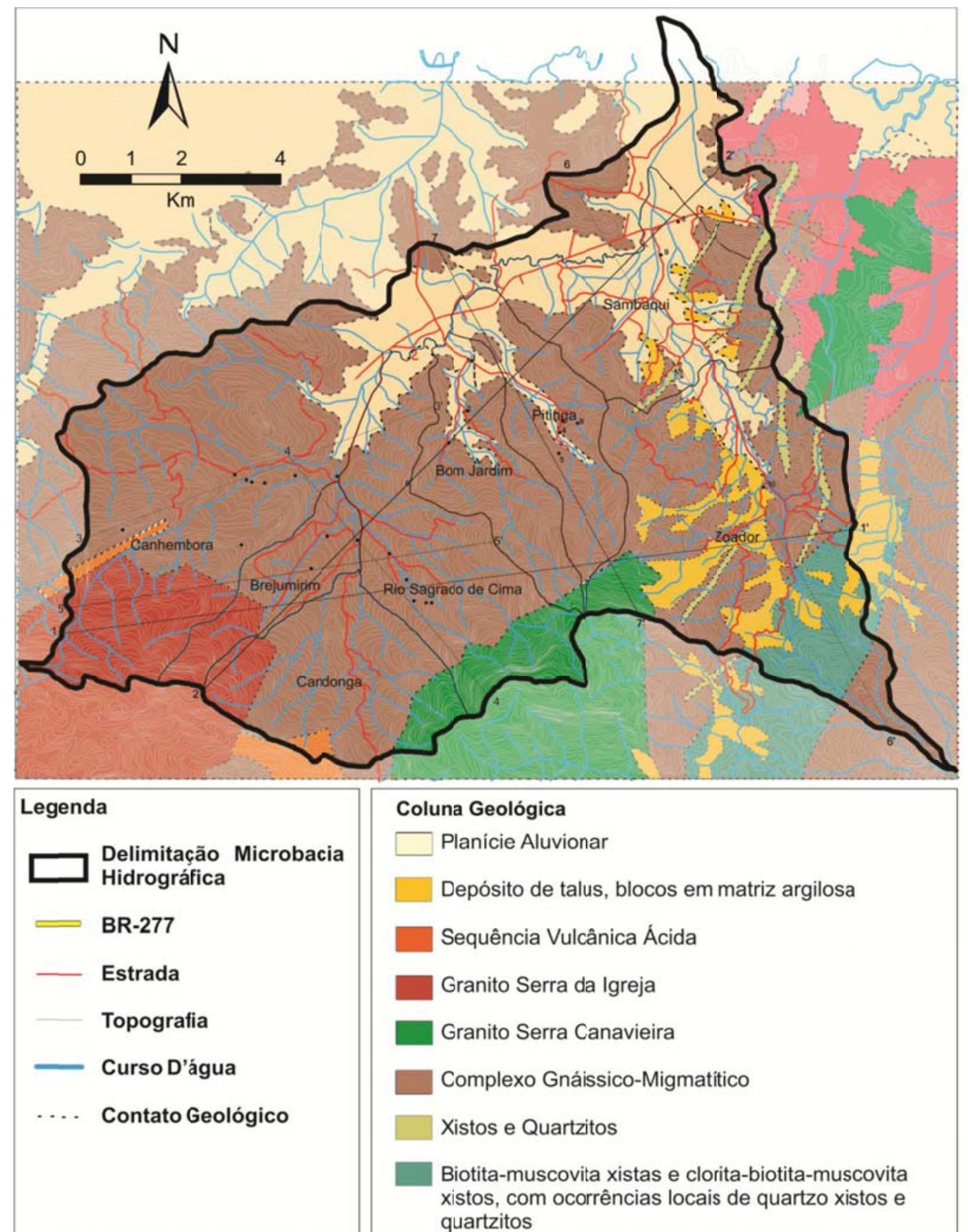

\section{Coluna Geológica}

Planície Aluvionar

Depósito de talus, blocos em matriz argilosa

Sequência Vulcânica Ácida

Granito Serra da Igreja

Granito Serra Canavieira

Complexo Gnáissico-Migmatitico

Xistos e Quartzitos

Biotita-muscovita xistas e clorita-biotita-muscovita xistos, com ocorrências locais de quartzo xistos e quartzitos

\section{Mapa Geológico}

Adaptado de Mapa Geoógico - Carta de Curitiba - MINEROPAR (2010).

Análise Socioambiental Partipativa Microbacia Hidrográfica do Rio Sagrado, Morretes (PR), zona laboratório de educação para o ecodesenvolvimento (ZEE).

Profs: Cristiane Mansur M. S., Juarês J. Aumond, Gilberto Friedenreich Santos. Bolsistas: Alice Garbari, Juliana Pilan, Samara Braun, Caroline Krug Vieira.

Figura 3- Mapa Geológico

Fonte: IPARDES, adaptado. 


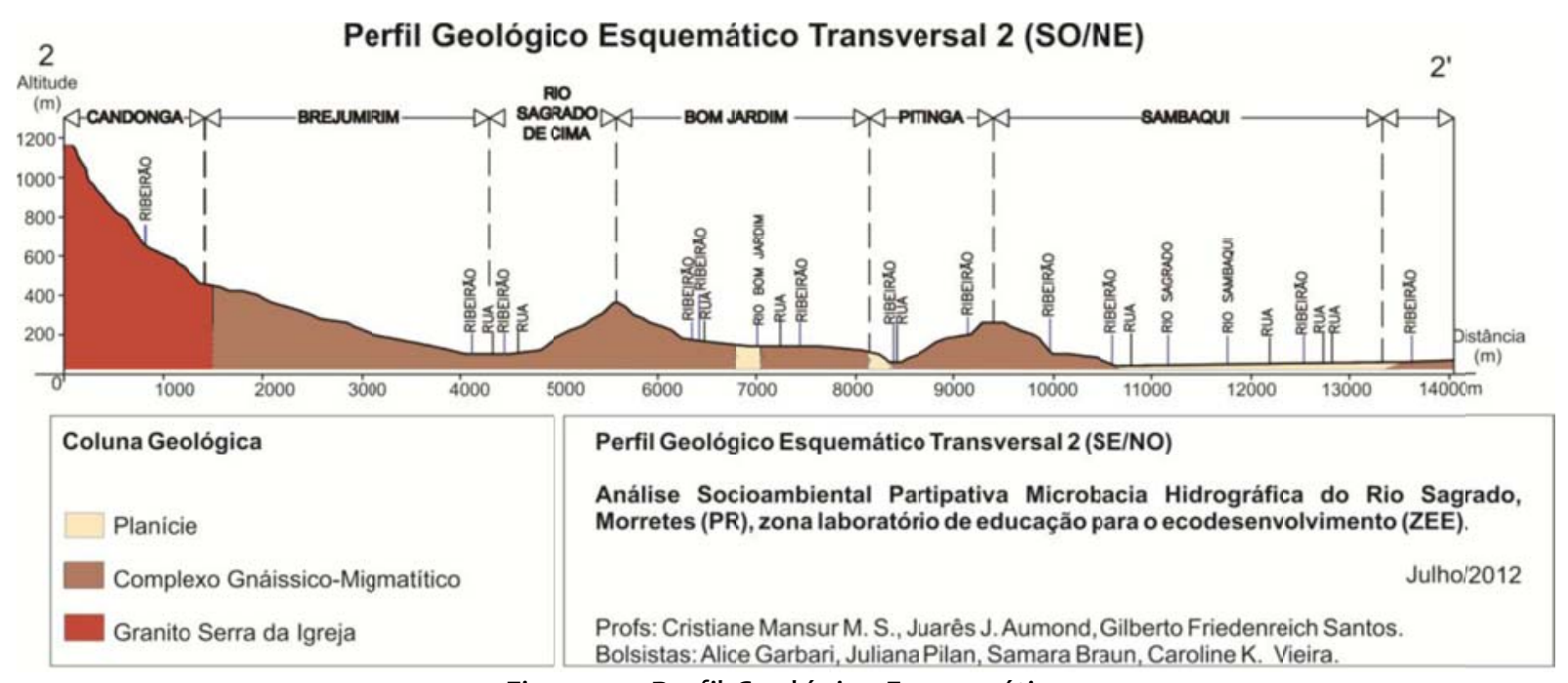

Figura 4 - Perfil Geológico Esquemático

Fonte: Resultado da Pesquisa - arquivo dos autores.

Por possuir declividade acentuada, a primeira unidade é considerada uma área de recepção dos movimentos de massa ocorridos nas partes mais elevadas das localidades vizinhas, fazendo com que o solo local torne-se bastante profundo.

Os movimentos de massas são processos da geodinâmica superficial no qual um movimento ou queda apreciável de material ocorre na presença da força gravitacional sobre uma superfície com determinado gradiente permitindo o acúmulo do material (ALVARADO, 2006).

No leito do rio, podem sem encontrados matacões em grande quantidade, evidenciando torrentes ocasionais e movimentos de massa antigos, sendo considerada vulnerável a inundações e torrentes (corridas de detritos) que facilmente chegam até a planície, pertencente à Segunda Unidade de Paisagem, devido à encosta possuir formato côncavo.

A ocupação humana, ainda que em menor escala comparada as porções mais baixas, sofre um aumento considerável principalmente na medida em que a declividade diminui, ocorrendo normalmente em torno dos rios e ribeirões, onde a vegetação já sofre com as a ações humanas sendo para a abertura de vias, que formam cortes bruscos nas encostas, ou para a prática de agricultura extensiva, que mesmo ocorrendo em maior intensidade nas áreas mais planas já comprometem as principais funções que o 
ecossistema presta ao local, tais como a contenção de erosão e ancoragem das encostas pelos sistemas radiculares das plantas.

\section{Segunda unidade de paisagem}

A segunda unidade de paisagem é a que predomina quase que em totalidade a Localidade de Sambaqui, o que a difere das demais localidades que se formam nos montantes mais altos da Microbacia do Rio Sagrado (Zoador, Pitinga, Bom Jardim, Rio Sagrado de Cima, Candonga, Brejumirim e Canhembora). Pode ser considerada a área mais habitada e explorada da Microbacia do Rio Sagrado, com considerável número de residências e forte indício da prática de agricultura.

Possui baixa declividade, chegando somente a $10^{\circ}$, e altitude com limite de 160 metros (figura 5). Geologicamente esta localidade apresenta Planícies Aluvionares e maiores variações petrográficas, ou seja, rochosa, como os migmatitos, os gnaisses e os xistos. O processo de intemperização das rochas é promovido devido a essa diversidade geológica e ao contato, gerado pelos mesmos, que adicionados aos processos deposicionais dos movimentos de massa, decorrentes das porções mais altas, originam solos bastante profundos.

\section{Perfil Geológico Esquemático Longitudinal 6 (SE/NO)}
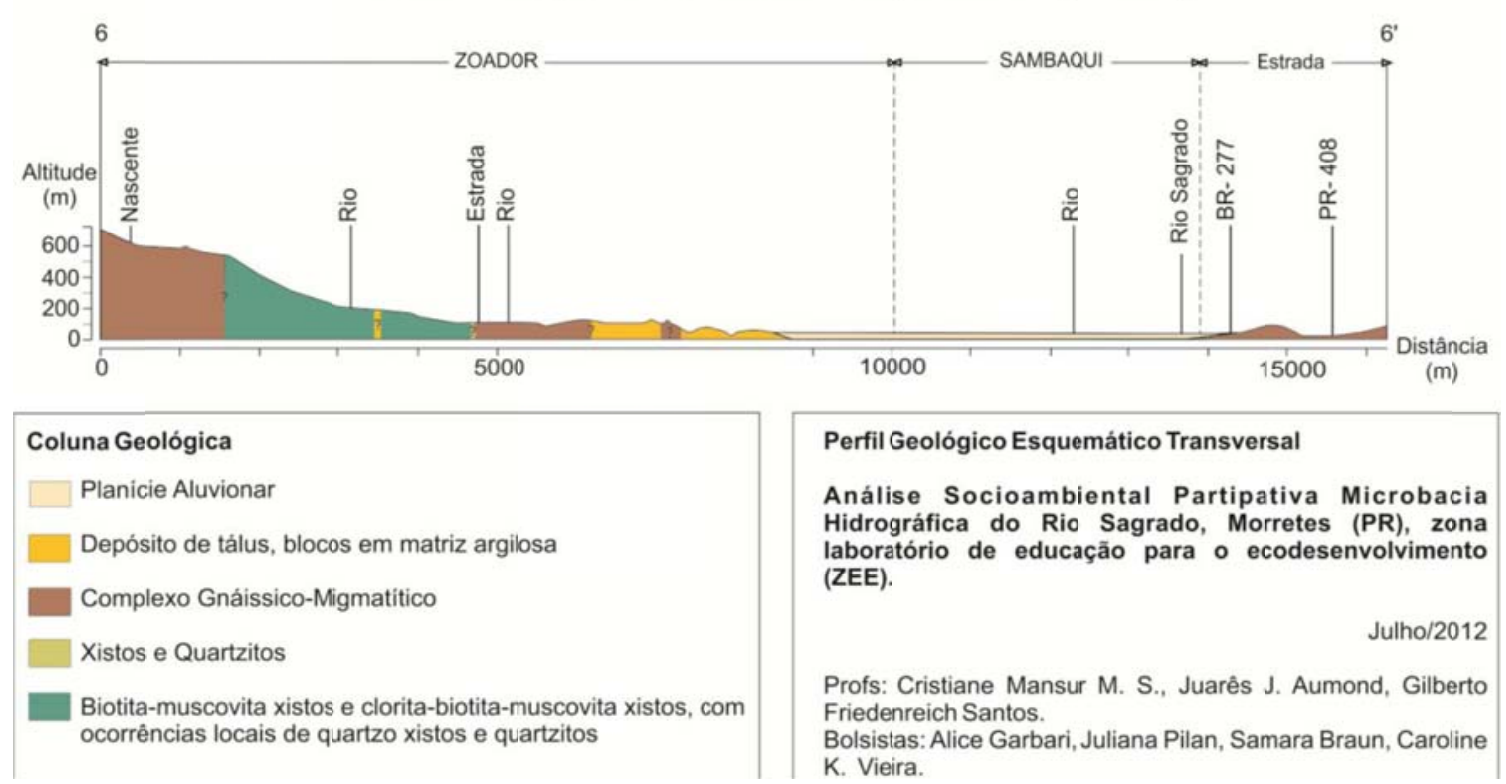

Figura 5- Perfil Geológico Esquemático Longitudinal Fonte: Resultado da Pesquisa - arquivo dos autores. 
Esta unidade de paisagem encontra-se mais a jusante da bacia hidrográfica e, portanto, está mais vulnerável a frequentes inundações e torrentes, principalmente nas áreas mais baixas e calhas de rios e ribeirões.

\section{Considerações finais}

O estudo em curso, realizado na Microbacia Hidrográfica do Rio Sagrado, tem sido catalisador para integração de diversos grupos de pesquisa promovendo a interdisciplinaridade e a multidisciplinaridade, como também permitiu avançar na direção da participação comunitária através da pesquisa e extensão buscando diagnósticos capazes de criar diretrizes que permitam amenizar os problemas locais.

A relação do homem com o meio ambiente evoluiu ao ponto da aceitação fatalista dos fenômenos naturais e da aplicação equivocada das tecnologias em busca do desenvolvimento desafiando as leis da natureza. Não se discute a ideia de que com o avanço tecnológico a população pode prevenir-se e melhor lidar com os desastres naturais, mas o que indaga a questão são as necessidades de conhecimento sobre tais ocorrências, mecanismos e medidas de prevenção.

De modo que antes da necessidade de remediar, deve-se prevenir. As análises realizadas nesta pesquisa, permitem-nos elaborar prognósticos que melhor direcionam o uso dos recursos naturais de forma mais racional possível, minimizando assim os efeitos causadas pelo homem na reordenação dos espaços físicos. A ação humana gera modificações no ambiente natural alterando seu equilíbrio que, apesar de não ser estático, parte de um dinamismo harmonioso. Essas modificações geram efeitos de agressão com graus correspondentes ao impacto gerado, sendo estes de diferentes níveis, levando às vezes as condições ambientais a processos irreversíveis (ROSS, 1990). Os principais casos desses impactos são detectados no mau uso do solo e da água nos quais são diagnosticados principalmente ocorrências de desmatamentos, erosão, poluição, etc.

Sachs (1986) também mencionou a ação preventiva sobre o ambiente como uma resultante bem mais barata do que medidas reparadoras, evitando o perigo de se 
perpetrar ambientes irreversíveis. Crescimento, desenvolvimento e preservação devem ser absolutamente planejados para poderem caminhar juntos.

Parte-se da premissa de que os processos geoambientais que interferem nas vertentes do Rio Sagrado, seus afluentes e encostas da Serra do Mar, se enquadram na observação feita por Sachs (1986) que considera que os impactos ambientais dependem da localização e da capacidade de carga dos ecossistemas relacionados ao clima, topografia, densidade de ocupação humana e econômica, padrões de uso da terra, etc. Para tanto, a análise socioambiental participativa dos fatores físico-naturais foram conjugados ao conhecimento científico e tradicional, resultando assim na identificação de áreas propícias à ocupação humana assim como as de maior sensibilidade presentes na microbacia em estudo.

Sendo assim, a Microbacia, como um todo, oferece às suas comunidades grandes riscos, que são agravados na medida em que a exploração e a ocupação indevidas aumentam. No entanto, Sambaqui, apesar de ser uma área suscetível a processos deposicionais, torrentes e inundações, pode ser caracterizada como propícia à ocupação humana e prática da agricultura por não oferecer riscos de deslizamento de massa e apresentar boa fertilidade do solo; deve-se levar em conta que a preservação do ecossistema local e, principalmente, das porções mais altas garantem segurança para os moradores e suas famílias.

\section{Referências}

ALVARADO, Luis Alonso Salas. Simulação bidimensional de corridas de detritos usando o método de elementos discretos. 2006. Dissertação ( Mestrado em...) - Pontifícia Universidade Católica do Rio de Janeiro, Rio de Janeiro, 2006.

ALVES, KELLER Flávia. Arranjo socioprodutivo de base comunitária: um projeto piloto na comunidade do entorno da micro-bacia do Rio Sagrado Morretes Paraná. 2008, oof. Dissertação (Mestrado em.... _ - Universidade Regional de Blumenau, Programa de Pósgraduação em Administração., 2008. 
AUMOND, Juarês José. Reflexões sobre a necessidade de uma nova abordagem na reconstrução dos ecossistemas degradados. In: TRES, D. R; REIS, A., (Org.) Perspectivas para a conservação e restauração do pontual ao contexto. Herbário Barbosa Rodrigues, Itajaí - SC, 2009, p. 45-60.

BARCELOS, Eduardo Álvaresda Silva.; BARRIEL, Maycon Cardoso. Práticas institucionais e grupos de interesse: a geograficidade da bancada ruralista e as estratégias hegemônicas no parlamento brasileiro. In: ENCONTRO NACIONAL DE GEOGRAFIA AGRÁRIA, 19, 2009. São Paulo. Anais ... São Paulo: 2009. Disponível em:

<http://www.geografia.fflch.usp.br/inferior/laboratorios/agraria/Anais\%20XIXENGA/artigo s/Barcelos_EAS.pdf $>$. Acesso em: ago. 2012.

BERTALANFFY, Ludwig Von. General systems theory. Foundations development, applications. New York: Braziller, 1968.

CARPANEZZI, Antonio Aparecido. Zoneamento ecológico para plantios florestais no Estado do Paraná. Brasília: EMBRAPA-CNPF, 1986.

FIGUEIREDO, Sebastião Virgílio de Almeida. Produção quantitativa e qualitativa de água: ação ambiental. Viçosa: UFV, 1999, n.3, p.7-8.

GARCIA, Rolando. Interdiciplinariedad y sistemas complejos. in: LEFF, Enrique. (org.). Ciencias sociales y formulación ambiental. Barcelona: Gedisa, 1994, p. 85-125.

HENRIQUÉZ Zuñiga, Christian Eduardo. et al. A utilização de indicadores socioambientais no processo de tomada de decisão para o desenvolvimento sustentável da micro-bacia do Rio Sagrado: relevância da interdisciplinaridade e transdisciplinaridade nas abordagens socioambientais. In: WORKSHOP INTERNACIONAL DE PESQUISA EM INDICADORES DE SUSTENTABILIDADE, 2, 2008. São Carlos. Anais ... São Carlos: USP.-, 2008.

LEFF, Enrique. Interdiciplinariedad y ambiente. In: . Ecologia y capital. México: Siglo XXI, 1994. p. 68-123

MALUF, R. S; ROSA, T. S. Mudanças climáticas, desigualdades sociais e populações vulneráveis no Brasil: Construindo Capacidades. Subprojeto Populações. Relatório Técnico 5. Volume 1. Rio de Janeiro: maio, 2011. Disponível em: <http://r1.ufrrj.br/cpda/ceresan/docs/Mudancas_climaticas,_desigualdades_sociais_e_pop ulacoes_vulneraveis_no_Brasil_construindo_capacidades_subprojeto_populacoes_(Volu me I).pdf >. Acessado em: ago. 2012. 
MUDANÇA do Clima no Brasil: Aspectos Econômicos, Sociais e Regulatórios. Secretaria de Assuntos Estratégicos da Presidência da República - Brasil. Brasília: IPEA, 2011. Disponível em:

<http://www.proac.uff.br/cede/sites/default/files/IPEA_2011_mudancadoclima_low.pdf> Acessado em: ago 2012.

NOWATZKI, Alexei; VEDOR DE PAULA, Eduardo; SANTOS, Leonardo José Cordeiro. Utilização do SIG delimitação das áreas de preservação permanente e avaliação do seu grau de conservação na Bacia Hidrográfica do Rio Sagrado (Morretes/PR). Sociedade \& Natureza, Uberlândia: UFU, v. 22, n. 1, p. 107-120, abr. 2010.

ROSS, Jurandyr Luciano Sanches. Geomorfologia: Ambiente e Planejamento. São Paulo: Contexto, 1990.

SACHS, Ignacy. Ecodesenvolvimento: Crescer sem destruir. São Paulo: Vertice, 1986.

SANTOS, Rozely Ferreira dos (Org.). Vulnerabilidade ambiental: Desastres naturais ou fenômenos induzidos? Brasília: MMA, 2007.

SEIXAS, Cristiana Simão. Abordagens e técnicas de pesquisa participativa em gestão e recursos naturais. In: VIEIRA, Paulo Freire; BERKES, Fkret; SEIXAS, Cristiana Simão (Org.) Gestão integrada e participativa de recursos naturais: conceitos, métodos e experiências. Florianópolis: Secco/APED, 2005, p 73-105.

SORRENTINO, Marco. De Tblissi a Thessalonikl: A Educação Ambiental no Brasil. In: CASCINO, Fábio; JACOBI, Pedro; OLIVEIRA, José Flávio de (Org.). Educação ambiental, meio ambiente e cidadania: reflexões e experiências. São Paulo: SMA/CEAM, 1998, p. 2734 .

TOLEDO, Victor Manuel Manzur; BARRERA-BASSOLS, Narciso. A etnoecologia: uma ciência pós-normal que estuda as sabedorias tradicionais. Revista Desenvolvimento e Meio Ambiente, Curitiba: UFPR, n. 20, p. 31- 45, jul./dez. 2009. 